\title{
sciforum
}

Conference Proceedings Paper

\section{Different methods for preparation of active sites in kaolinite surface and their usability in photocatalytic processes}

\author{
Veronika Vágvölgyi ${ }^{1 *}$, Balázs Zsirka ${ }^{1}$, Katalin Győrfi ${ }^{1}$, Erzsébet Horváth ${ }^{1}$ and János Kristóf ${ }^{1}$ \\ 1 Laboratory for Surfaces and Nanostructures; Research Centre for Biochemical, Environmental and \\ Chemical Engineering; University of Pannonia \\ * Correspondence: vagvolgyiv@almos.uni-pannon.hu
}

Received: date; Accepted: date; Published: date

\begin{abstract}
A relevant discovery of the last decade is the identification of the photochemical activity of the kaolinite-type minerals. The activity depends on several surface properties, such as mineral composition, morphology, lattice impurities and structural order. Preparation of the activated surface can be made by intercalation, exfoliation, mechanochemical activation, acid treatment, thermal treatment. The process of intercalation is a well-known way for a long while to produce delaminated and finally exfoliated structure from double-layered minerals. Coordination of octahedral $\mathrm{Al}$ atoms can be reduced by means of mechanochemical activation (i. e. dry grinding) and/or thermal treatment. The (hydrochloric) acid treatment alters not only the acid-base properties of the surface, but has effect on the mineral composition also. In this study the influence of the mentioned surface modification methods is shown on kaolins from different deposits with varying structural order, mineral and lattice impurities. The modified surface is investigated with thermal analysis (TG-DTG, CRTA), XRD, solid phase NMR and IR spectroscopic techniques. Photocatalytic activity is tested in liquid phase with oxalic acid test molecule during $365 \mathrm{~nm}$ irradiation. Applying and combining various surface modification methods it is possible to enhance the natural kaolin-based materials in order to develop photocatalysts.
\end{abstract}

Keywords: kaolinite; mechanochemical activation; thermal treatment; acid treatment; photocatalytic activity

\section{Introduction}

Kaolinite is a 1:1 type layered silicate with the general formula $\mathrm{Al}_{2} \mathrm{Si}_{2} \mathrm{O}_{5}(\mathrm{OH})_{4}$ consisting of a two-dimensional arrangement of Si-centered tetrahedra and a two-dimensional arrangement of Al-centered octahedra. The double layers held together via $\mathrm{H}$ bonds show a parallel orientation along the ' $c$ ' axis (book-type arrangement). The basal distance is around 7.1 $\AA$. The $\mathrm{H}$ bonds can be broken up with suitable reagent leading to the formation of intercalation complexes. With cascade intercalation the clay can be separated to individual double layers (exfoliation) [1].

The discovery of the photocatalytic activity of the 1:1 type clay minerals in the last decade provides new facilities in application such as photocatalytic materials [2, 3].. The activity of the surface is closely related to the number and the acid-base properties of the defect sites, i.e. the alteration of coordination number of the $\mathrm{Al}$ atoms [4]. Preparation of defect sites is possible in different ways, such as (i) intercalation/exfoliation (the $\mathrm{Al}$ atoms of octahedral sheets will be more available), (ii) mechanochemical activation i.e. dry grinding [5], (iii) thermal treatment [6] and (iv) acid treatment [7] and (v) combination of methods above. 
In this study we are focusing the effect of mechanochemical activation on the active (defect) sites using different type of kaolin (from different deposits).

\section{Materials and Methods}

The investigated kaolins are originated from different deposits: (i) kaolin1 (Surmin, Poland) (ii) kaolin2 (Sedlec also known as Zettlitz, Czech Rep.), (iii) kaolin3 (Szegilong, Hungary) and (iv) kaolin4 (Felsőpetény, Hungary). Oxide composition of the kaolins:

kaolin1: $34 \% \mathrm{Al}_{2} \mathrm{O}_{3} ; 52 \% \mathrm{SiO}_{2}, 0.6 \% \mathrm{TiO}_{2}, 0.6 \% \mathrm{Fe}_{2} \mathrm{O}_{3},<1 \%$ for $\mathrm{MgO}, \mathrm{CaO}, \mathrm{K}_{2} \mathrm{O}$ and $\mathrm{Na}_{2} \mathrm{O}$

kaolin2: $37 \% \mathrm{Al}_{2} \mathrm{O}_{3} ; 46 \% \mathrm{SiO}_{2}, 0.9 \% \mathrm{Fe}_{2} \mathrm{O}_{3},<1 \%$ for $\mathrm{TiO}_{2}, \mathrm{MgO}, \mathrm{CaO}, \mathrm{K}_{2} \mathrm{O}$ and $\mathrm{Na}_{2} \mathrm{O}$

kaolin3: $34 \% \mathrm{Al}_{2} \mathrm{O}_{3} ; 47 \% \mathrm{SiO}_{2}, 3.2 \% \mathrm{Fe}_{2} \mathrm{O}_{3},<1 \%$ for $\mathrm{TiO}_{2}, \mathrm{MgO}, \mathrm{CaO}, \mathrm{K}_{2} \mathrm{O}$ and $\mathrm{Na}_{2} \mathrm{O}$

kaolin4: $33 \% \mathrm{Al}_{2} \mathrm{O}_{3} ; 56 \% \mathrm{SiO}_{2}, 1.9 \% \mathrm{TiO}_{2}, 7 \% \mathrm{Fe}_{2} \mathrm{O}_{3},<1 \%$ for $\mathrm{MgO}, \mathrm{CaO}, \mathrm{K}_{2} \mathrm{O}$ and $\mathrm{Na}_{2} \mathrm{O}$

The kaolin 1-2-4 contain more than $90 \%$ kaolinite (mineral impurities are mainly illite, albite, ortoclase, muscovite) and show tabular morphology. Kaolin3 has high (almost 50\%) halloysite content beside kaolinite showing tubular morphology. It is important to highlight that kaolin4 has considerable iron content as mineral impurity (goethite, hematite) and lattice impurity. The four kaolinite differ in structural order, too. The structural order is described with the Hinckley-index, which are 1.4, 0.8, 0.3 and 1.4 for kaolin1, 2, 3 and 4, respectively.

Exfoliation (cascade intercalation) is made with K-acetate, ethylene-glycol, hexylamine, and toluene according to reference [1]. The exfoliated samples are referred "nanokaolinite". Efficiency of exfoliation was complete for kaolin1-2-3, but for kaolin4 it was only 38\% possibly due to the lattice iron impurity [1].

Mechanochemical activation is made in planetary mill in $\mathrm{Al}_{2} \mathrm{O}_{3}$ pot $\left(80 \mathrm{~cm}^{3}\right)$ with $\mathrm{Al}_{2} \mathrm{O}_{3}$ balls. The kaolin:ball mass ratio was 1:4 ( $3 \mathrm{~g}$ of kaolin and 12 balls). The applied grinding time was 15, 60, 120 and 300 minutes with 400rpm.

Thermal treatment was carried out in a thermobalance (Derivatograph PC, MOM, Hungary), that provides possibility to follow the thermal behavior during the heating. The measurements were carried out in open ceramic crucible in static air atmosphere. Under dynamic conditions the heating rate was $5^{\circ} \mathrm{C} / \mathrm{min}$. Under CRTA (controlled rate thermal analysis) conditions the pre-set decomposition rate was $0.05 \mathrm{mg} / \mathrm{min}$, under this threshold the heating was linear $\left(1^{\circ} \mathrm{C} / \mathrm{min}\right)$. With CRTA technique it is possible to distinguish the closely overlapping decomposition steps.

Acid treatment was applied to reduce the iron-content of the kaolin3. 20g of kaolin was stirred with concentrated $\mathrm{HCl}$ for 3 hours at room temperature. The treated kaolin was filtered and washed with deionized water until the filter-liquor was colorless. The filtered kaolin was dried on air.

Solid phase ${ }^{27} \mathrm{Al}$ NMR measurements were carried out to follow the alteration of coordination number of $\mathrm{Al}$ atoms using a Bruker Avenece $9.4 \mathrm{~T}$ spectrometer equipped with a $4 \mathrm{~mm}$ MAS BBO probe-head. The spinning frequency was varied between 8 and $12 \mathrm{kHz}$ to differentiate peaks and spinning sidebands.

Surface area investigation was carried out to find out the alteration of the specific surface area and pore structure during the treatment. These were measured using a Micromeritics ASAP 2000-type instrument on samples of $\sim 1 \mathrm{~g}$, outgassed in vacuum at $60^{\circ} \mathrm{C}$. Pretreatment was completed when the vacuum pressure dropped below $10^{-5}$ torr.

\section{Results}

\subsection{Thermal behaviour}

Thermogravimetric (TG), and its derivative (DTG) curves were made about the untreated, ground, nanokaolinite and ground-nanokaolinite samples. Only the kaolin2 sample's curves are presented here (Figure 1). The other three samples behave similarly. It is interesting to investigate the DTG curves of kaolin4 (high iron-content) sample (Figure 2). A summary is made about the peak temperature of the dehydroxylation (Table 1). 


\section{2. ${ }^{27}$ Al MAS NMR measurements}

In order to find out the alteration of coordination number of $\mathrm{Al}$ atoms solid state NMR measurements were made about the untreated, ground for 5h, nanokaolinite and ground(for 5h)-nanokaolinite samples. The results can be seen in Figure 3. We investigated the peaks belong to the $\mathrm{Al}(\mathrm{VI})$ ( 0 ppm), the $\mathrm{Al}(\mathrm{V})(\sim 30 \mathrm{ppm})$ and the $\mathrm{Al}(\mathrm{IV})(50-70 \mathrm{ppnm})$ atoms. Peak intensities are not represents the quantity of different Al coordinations, only the presence of them can be followed.

\subsection{Specific surface area (SSA) measurements}

In SSA measurements we investigated the change in specific surface area (BET and BJH) and the pore size structure caused by the exfoliation and grinding. Results are summarized in Table 2.

\section{Discussion}

\subsection{Thermal analysis}

Untreated kaolin samples show two decomposition steps: (i) around $100^{\circ} \mathrm{C}$ dehydration and (ii) around $500^{\circ} \mathrm{C}$ dehydroxylation takes place (Figure 1 a). In dehydroxylation process structural $\mathrm{OH}$-groups eliminate as water resulting $\mathrm{Al}$ atoms with reduced coordination number. After exfoliation, in case of nanokaolinite samples the first mass loss step is broader, because the dehydration process overlaps with the decomposition of the remaining intercalation reagent (Figure $1 \mathrm{~b})$.

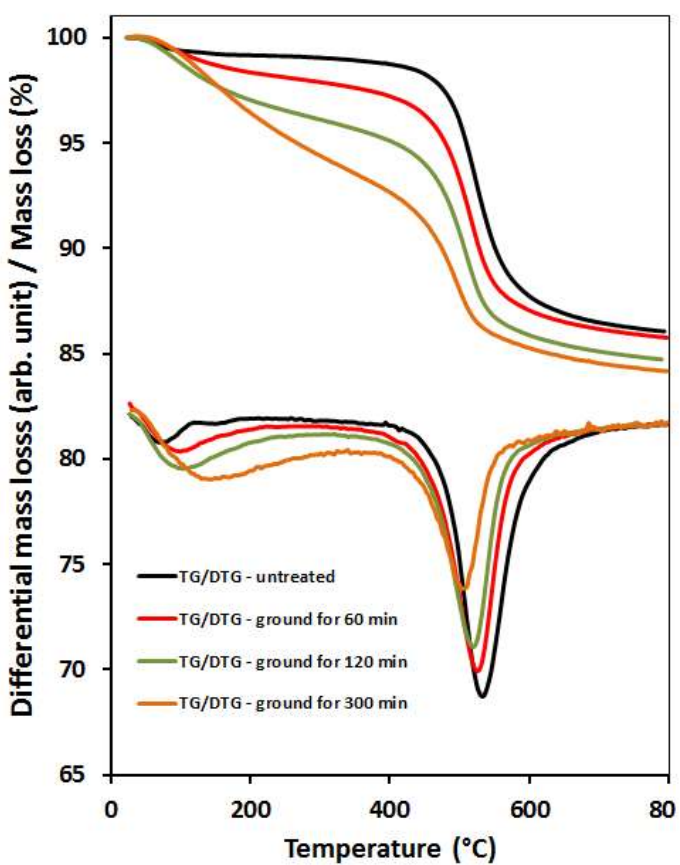

a)

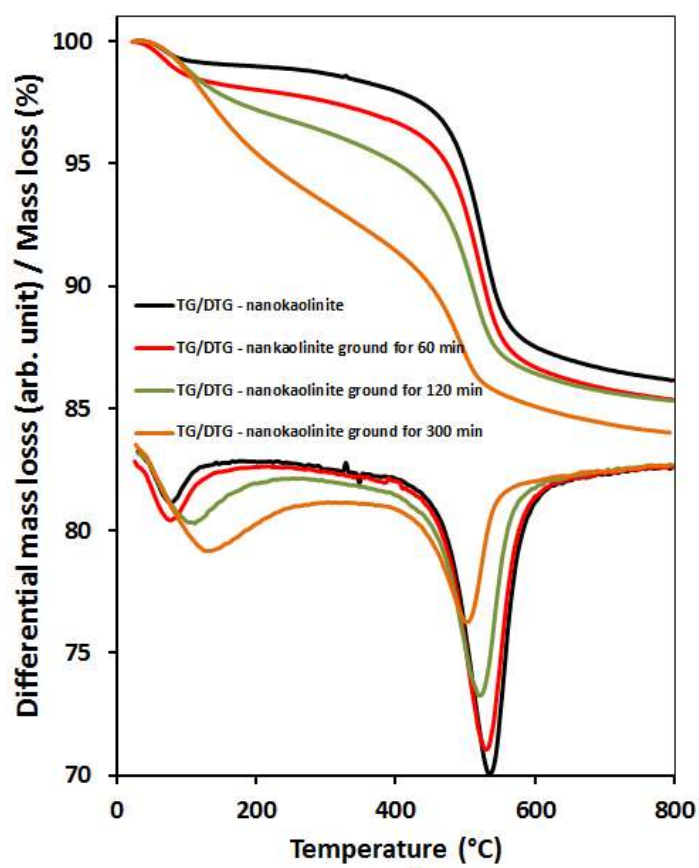

b)

Figure 1. TG/DTG curves of kaolin2 samples. (a) untreated and ground for 60, 120, and 300 minutes; (b) exfoliated and ground-exfoliated.

After grinding the amount of adsorbed water has increased at the expense of dehydroxylation and the peak of its temperature shifts to the lower values (Table 1). The shift is around $20-40^{\circ} \mathrm{C}$ for each sample after 300 min grinding. During dry grinding the impinging sample particles may heat up to the temperature of dehydroxylation $\left(500^{\circ} \mathrm{C}\right)$, the resulting water (generated from the eliminating $\mathrm{OH}$ groups) can strongly bond to the active sites ( $\mathrm{Al}$ atoms with reduced coordination $[8,9]$. 
Table 1. Peak temperature of dehydroxylation for all kaolin samples.

\begin{tabular}{|c|c|c|}
\hline Sample & Treatment & $\begin{array}{c}\text { Peak temperature } \\
\text { of dehydroxylation }\left({ }^{\circ} \mathrm{C}\right)\end{array}$ \\
\hline \multirow[t]{4}{*}{ kaolin1 } & untreated & 527 \\
\hline & ground for $300 \mathrm{~min}$ & 490 \\
\hline & nanokaolinite & 522 \\
\hline & nanokaolinite ground for $300 \mathrm{~min}$ & 492 \\
\hline \multirow[t]{4}{*}{ kaolin2 } & untreated & 521 \\
\hline & ground for $300 \mathrm{~min}$ & 496 \\
\hline & nanokaolinite & 523 \\
\hline & nanokaolinite ground for $300 \mathrm{~min}$ & 492 \\
\hline \multirow[t]{4}{*}{ kaolin3 } & untreated & 510 \\
\hline & ground for $300 \mathrm{~min}$ & 487 \\
\hline & nanokaolinite & 515 \\
\hline & nanokaolinite ground for $300 \mathrm{~min}$ & 492 \\
\hline \multirow[t]{7}{*}{ kaolin4 } & untreated & 507 \\
\hline & ground for $300 \mathrm{~min}$ & 463 \\
\hline & nanokaolinite & $443 / 563^{1}$ \\
\hline & nanokaolinite ground for $300 \mathrm{~min}$ & $425 / 518^{1}$ \\
\hline & acid treated & 510 \\
\hline & acid treated ground for $300 \mathrm{~min}$ & 470 \\
\hline & acid treated nanokaolinite & $470 / 561^{1}$ \\
\hline
\end{tabular}

${ }^{1}$ The dehydroxylation has been broken up into two steps after exfoliation.

It is interesting to observe the thermal behavior of kaolin4 sample (Figure 2). The untreated sample has a third decomposition step at around $300^{\circ} \mathrm{C}$. This step can be identified as the mineral impurity of goethite's decomposition. After acid treatment the goethite disappears, there is no any decomposition in this temperature range. After exfoliation, the nanokaolinite 4 sample show two dehydroxylation processes. The two processes belong to the dehydroxylation of the exfoliated and the non-exfoliated phases. Let us observe the dehydroxylation process of the untreated or the acid treated kaolin4 sample: the DTG peak in this temperature range is asymmetric, that means energetically different, but closely overlapping decomposition processes take place. With CRTA (controlled rate thermal analysis) it was possible to distinguish these overlapping steps [10].

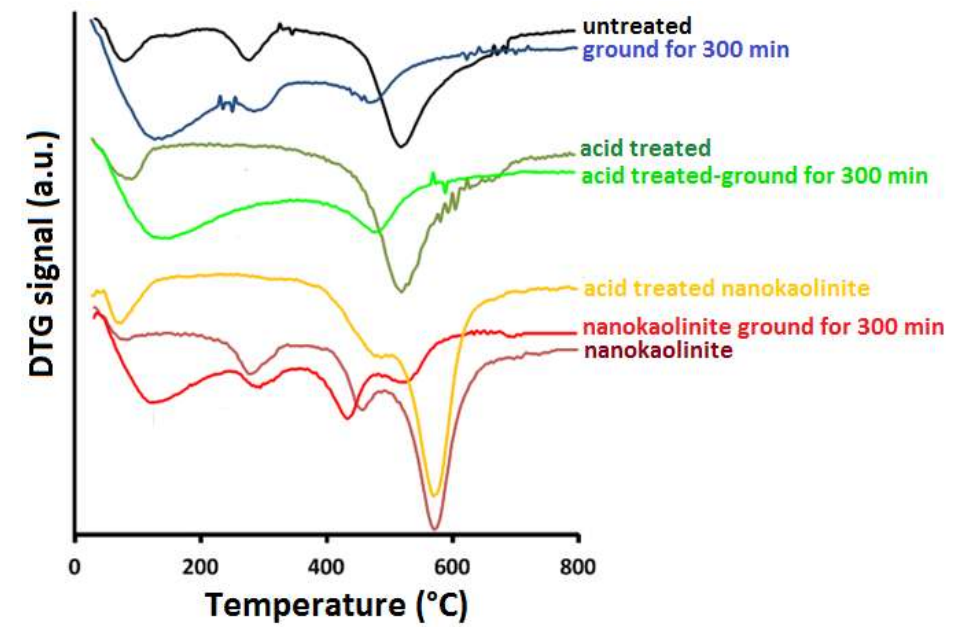

Figure 2. DTG curves of kaolin4 samples. 


\section{2. ${ }^{27}$ Al MAS NMR measurements}

$\mathrm{Al}$ atoms are mostly octahedral in the kaolinite structure, but in small quantity $\mathrm{Al}(\mathrm{IV})$ coordination also occurs due to possible Al substitution in tetrahedral sheets. After exfoliation the NMR spectra show similar pattern (Figure 3), so the cascade intercalation has no significant influence inside the double layers. After grinding a significant increase of quantity of $\mathrm{Al}(\mathrm{V})$ and $\mathrm{Al}(\mathrm{IV})$ coordination has been observed, even the peak of $\mathrm{Al}(\mathrm{VI})$ around 0 ppm has been distorted and shifted to higher ppm values. The ground and ground-exfoliated samples' spectra are similar, suggesting that we can produce the same active sites on 2D (exfoliated) or 3D (non-exfoliated) structure. Of course in exfoliated state the availability of the active sites is prosperous.

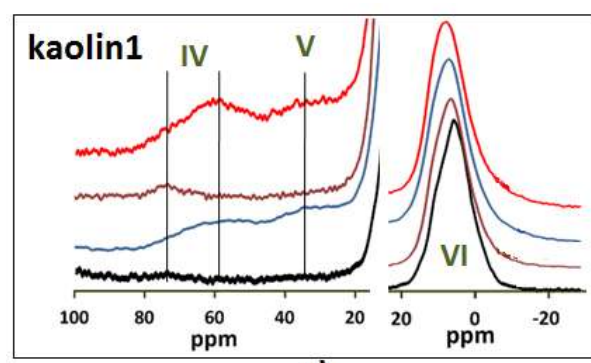

a)

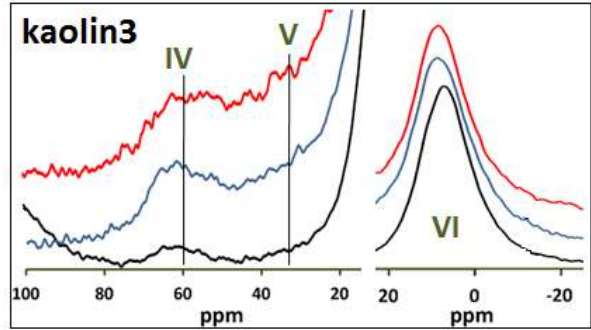

c)

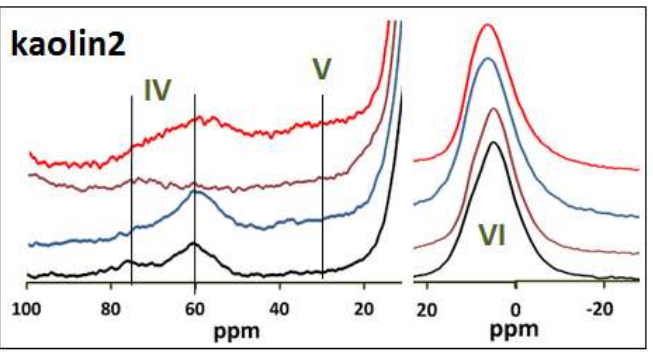

b)

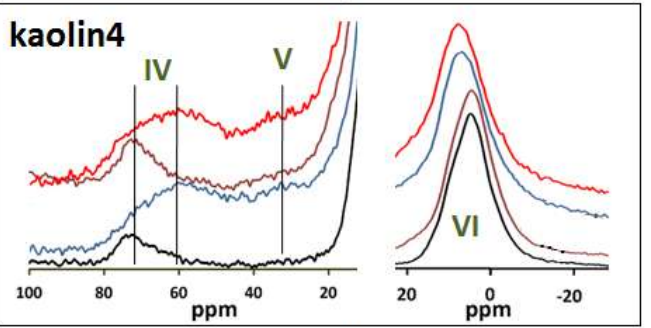

d)

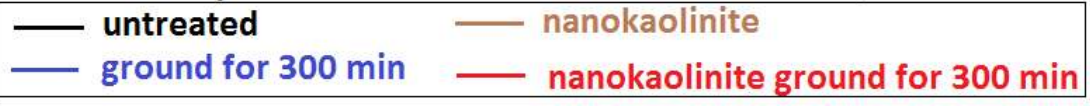

Figure 3. ${ }^{27} \mathrm{Al}$ MAS NMR spectra of kaolin samples. (a) kaolin1; (b) kaolin2; (c) kaolin3 (spectrum of nanokaolinite sample has not been measured; (d) kaolin4.

\subsection{Specific surface area measurements}

According to the later application of the prepared surface, it is important to investigate the specific surface area and the pore structure. The quantity of the available surface sites is in close connection with the reactivity. Thus BET surface area, average pore diameter (Table 2) and pore size distribution measurements were also made. The increased surface area is useful, but only if the pores are in the mesoporous size range. Micropores are not available for the most molecules.

The four kaolins have different surface area: kaolin3 has the highest initial surface area while kaolin 2 and kaolin4 have the lowest, though after grinding kaolin2 and kaolin3 have similar surface area. Kaolin4's surface area is rather low even after grinding.

Exfoliation has no significant influence on the surface area seemingly. This unexpected result can be due to the morphological change during exfoliation: the initial tabular structure turns into tubular, that making more difficult to access the surface.

The average pore diameter decreased slightly during grinding, the pore size distribution has showed shift to the micropore size range. 
Table 2. Specific surface area values measured and calculated according to the BET (Brunauer-Emmett-Teller) method and average pore diameter (D) values for non-ground and ground (for 120 and $300 \mathrm{~min}$ ) samples.

\begin{tabular}{|c|c|c|c|c|c|c|}
\hline \multirow{2}{*}{ Property } & $0 \mathrm{~min}$ & $120 \mathrm{~min}$ & $300 \mathrm{~min}$ & $0 \mathrm{~min}$ & $120 \mathrm{~min}$ & $300 \mathrm{~min}$ \\
\hline & \multicolumn{3}{|c|}{ Kaolin1 } & \multicolumn{3}{|c|}{ Nanokaolinite1 } \\
\hline BET surface $\left(\mathrm{m}^{2} / \mathrm{g}\right)$ & 31 & 34 & 43 & 28 & 36 & 55 \\
\hline \multirow[t]{2}{*}{ Daverage $(\mathrm{nm})$} & 13.5 & 12.2 & 11.2 & 13.4 & 11.5 & 10.9 \\
\hline & \multicolumn{3}{|c|}{ Kaolin2 } & \multicolumn{3}{|c|}{ Nanokaolinite2 } \\
\hline BET surface $\left(\mathrm{m}^{2} / \mathrm{g}\right)$ & 19 & 56 & 71 & 22 & 40 & 58 \\
\hline \multirow[t]{2}{*}{ Daverage $(\mathrm{nm})$} & 14.4 & 11.2 & 9.9 & 15.1 & 11.3 & 10.3 \\
\hline & \multicolumn{3}{|c|}{ Kaolin3 } & \multicolumn{3}{|c|}{ Nanokaolinite3 } \\
\hline BET surface $\left(\mathrm{m}^{2} / \mathrm{g}\right)$ & 50 & 56 & 69 & 43 & 60 & 66 \\
\hline \multirow[t]{2}{*}{ Daverage $(\mathrm{nm})$} & 14.3 & 11.1 & 10 & 15.7 & 10.7 & 11.5 \\
\hline & \multicolumn{3}{|c|}{ Kaolin4 } & \multicolumn{3}{|c|}{ Nanokaolinite4 } \\
\hline BET surface $\left(\mathrm{m}^{2} / \mathrm{g}\right)$ & 17 & 31 & 29 & 14 & 27 & 31 \\
\hline Daverage $(\mathrm{nm})$ & 11.6 & 10.1 & 10.8 & 12.9 & 11.1 & 11.7 \\
\hline
\end{tabular}

\section{Conclusions}

Applying mechanochemical activation, i.e. dry grinding it is possible to generate active sites in kaolinite structures. With NMR spectroscopy reduced coordination number of $\mathrm{Al}$ atoms was detected. SSA measurements have also showed increased surface area, but the change of pore structure was not favorable (shift to the micropore size range). Thus mechanochemical activation is too drastic to generate active sites without structural disruption.

Acknowledgments: Access to powder X-ray diffraction and NMR spectroscopic and instrumentation at the University of Pannonia is acknowledged. The authors thank the Agyag-Ásvány GmbH (Felsőpetény, Hungary) for the kaolin samples. Financial supports from the GINOP-2.3.2-15-2016-00016 and GINOP-2.3.2-15-2016-00053 projects (co-financed by the Széchenyi 2020 program) are also acknowledged.

Conflicts of Interest: The authors declare no conflict of interest. 


\section{References}

1. Zsirka, B.; Horváth, E.; Makó, É.; Kurdi, R.; Kristóf, J. Preparation and characterization of kaolinite nanostructures: reaction pathways, morphology and structural order. Clay Minerals 2015, 50, 329-340.

2. Szabó, P.; Zsirka, B.; Fertig, D.; Horváth, E.; Csizmadia, T.; Kristóf, J. Delaminated kaolinites as potential photocatalysts: Tracking degradation of Na-benzenesulfonate test compound adsorbed on the dry surface of kaolinite nanostructures. Cat. Today 2017, 287, 37-44.

3. Kibanova D.; Trejo M.; Destaillats H.; Cervini-Silva J.: Photocatalytic Activity of Kaolinite. Catal. Commun. 2011, $12(8), 698-702$.

4. Zsirka, B.; Táborosi, A.; Szabó, P.; Szilágyi, R.K.; Horváth, E.; Juzsakova, T.; Kristóf, J. Surface Characterization of Mechanochemically Modified Exfoliated Halloysite Nanoscrolls. Langmuir 2017, 33, 3534-3547.

5. Frost, R.L.; Makó, É.; Kristóf, J.; Horváth, E. Mechanochemical Treatment of Kaolinite. J. Colloid Interface Sci. 2001, 239(2), 458-466

6. Vágvölgyi, V.; Kovács, J.; Horváth, E.; Kristóf, J.; Makó, É. Investigation of mechanochemically modified kaolinite surfaces by thermoanalytical and spectroscopic methods. J. Colloid Interface Sci. 2008, 317 (2) 523-529.

7. Belver, C.; Munoz, M.A.B.; Vicente, M.A. Chemical Activation of a Kaolinite under Acid and Alkaline Conditions. Chem. Mater. 2002, 14, 2033-2043.

8. Horváth, E; Frost, R.L.; Makó, É.; Kristóf, J.; Cseh T. Thermal treatment of mechanochemically activated kaolinite. Thermochimica Acta 2003, 404, 227-234

9. Horváth, E; Kristóf, J.;Frost, R.L.; Jakab, E. Identification of superactive centers in thermally treated formamide-intercalated kaolinite. J. Colloid Interface Sci. 2005, 289(1), 132-138

10. Vágvölgyi, V.; Győrfi, K.; Zsirka, B.; Horváth, E.; Kristóf, J. The role of thermal analysis in the development of high-iron-content. kaolinite-based photocatalysts J. Colloid Interface Sci. 2020, 142, 289-299.

(C) 2020 by the authors. Submitted for possible open access publication under the terms and conditions of the Creative Commons Attribution (CC BY) license (http://creativecommons.org/licenses/by/4.0/). 